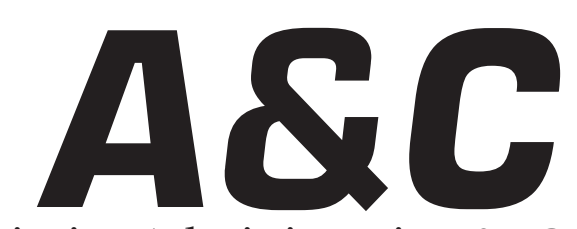

Revista de Direito Administrativo \& Constitucional

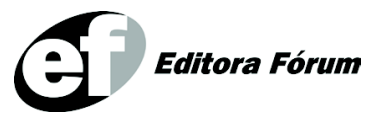

ISSN $1516-3210$ 


\section{A\&C REVISTA DE DIREITO ADMINISTRATIVO E CONSTITUCIONAL}

IPDA

Instituto Paranaense

de Direito Administrativo

Direção Geral

Romeu Felipe Bacellar Filho

Direção Editorial

Paulo Roberto Ferreira Motta

Direção Executiva

Emerson Gabardo

Conselho de Redação

Edgar Chiuratto Guimarães

Adriana da Costa Ricardo Schier

Célio Heitor Guimarães

\section{Conselho Editorial}

Adilson Abreu Dallari

Alice Gonzáles Borges

Carlos Ari Sundfeld

Carlos Ayres Britto

Carlos Delpiazzo

Cármen Lúcia Antunes Rocha

Celso Antônio Bandeira de Mello

Clèmerson Merlin Clève

Clóvis Beznos

Enrique Silva Cimma

Eros Roberto Grau

Fabrício Motta

Guilhermo Andrés Muñoz (in memoriam)

Jaime Rodríguez-Arana Muñoz

Jorge Luís Salomoni

José Carlos Abraão
José Eduardo Martins Cardoso
José Luís Said
José Mario Serrate Paz
Juan Pablo Cajarville Peruffo
Juarez Freitas
Julio Rodolfo Comadira
Luís Enrique Chase Plate
Lúcia Valle Figueiredo
Manoel de Oliveira Franco Sobrinho
(in memoriam)
Marçal Justen Filho
Marcelo Figueiredo
Márcio Cammarosano
Maria Cristina Cesar de Oliveira

Nelson Figueiredo

Odilon Borges Junior

Pascual Caiella

Paulo Eduardo Garrido Modesto

Paulo Henrique Blasi

Paulo Neves de Carvalho (in memoriam)

Paulo Ricardo Schier

Pedro Paulo de Almeida Dutra

Regina Maria Macedo Nery Ferrari

Rogério Gesta Leal

Rolando Pantoja Bauzá

Sérgio Ferraz

Valmir Pontes Filho

Yara Stropa

Weida Zancaner

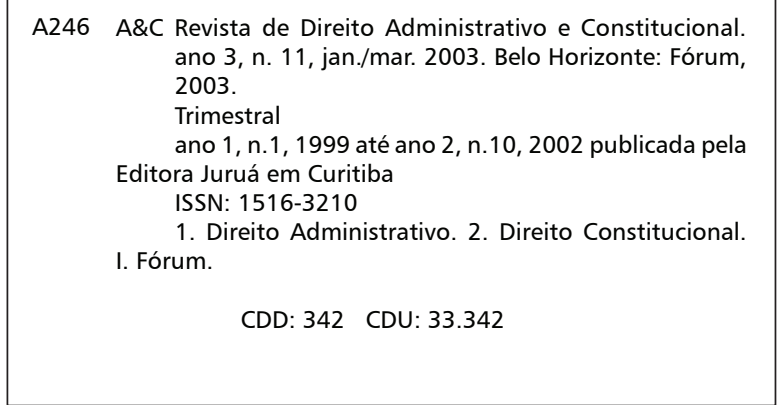

(c) Editora Fórum Ltda. 2006

Todos os direitos reservados. É proibida a reprodução total ou parcial, de qualquer forma ou por qualquer meio eletrônico ou mecânico, inclusive através de processos xerográficos, de fotocópias ou de gravação, sem permissão por escrito do possuidor dos direitos de cópias (Lei $n^{\circ}$ 9.610, de 19.02.1998).

\section{Editora Fórum Ltda}

Av. Afonso Pena, 2770 - 15\%16ªndar - Funcionários

CEP 30130-007 - Belo Horizonte/MG - Brasil

Tel.: 08007043737

Internet: www.editoraforum.com.br

e-mail: editoraforum@editoraforum.com.br
Editor responsável: Luís Cláudio Rodrigues Ferreira Projeto gráfico e diagramação: Luis Alberto Pimenta Revisora: Olga M. A. Sousa

Pesquisa jurídica: Fátima Ribeiro - OAB/MG 74868

Bibliotecária: Alessandra Rodrigues da Silva CRB 2778/MG 6 ${ }^{\text {a Região }}$

Os conceitos e opiniões expressas nos trabalhos assinados são de responsabilidade exclusiva de seus autores.

Impressa no Brasil / Printed in Brazil

Distribuída em todo Território Nacional 


\title{
A efetivação do direito à saúde por uma jurisdição-serafim: limites e possibilidades
}

Rogério Gesta Leal

Desembargador do Tribunal de Justiça do Estado do Rio Grande do Sul. Doutor em Direito, Professor Titular da Universidade de Santa Cruz do Sul, Professor Colaborador da Universidade Estácio de Sá. Professor Visitante da Università Túlio Ascarelli - Roma-Tre, Universidad de La Coruña - Espanha e Universidad de Buenos Aires

\author{
Não serei o poeta de um mundo caduco. \\ Também não cantarei o mundo futuro. \\ Estou preso à vida e olho meus companheiros. \\ Estão taciturnos, mas nutrem grandes esperanças. \\ Entre eles, considero a enorme realidade. \\ O presente é tão grande, não nos afastemos. \\ Não nos afastemos muito, vamos de mãos dadas.*
}

\begin{abstract}
Sumário: 1 Notas introdutórias - 2 A saúde como direito fundamental - 3 Perspectivas institucionais do dever prestacional da saúde no Brasil - 4 O caso concreto e sua solução - Referências
\end{abstract}

Palavras-chave: Direito à saúde. Recursos públicos. Poder Judiciário. Gestão de saúde.

\section{Notas introdutórias}

O presente ensaio pretende abordar a tormentosa questão do direito à saúde no Brasil sob a perspectiva de sua efetivação pelo Poder Judiciário. Para tanto, vai-se delimitar o objeto de análise em termos normativos e institucionais, verificando, primeiro, de que forma o sistema jurídico brasileiro aloca a saúde em face do Estado e da Sociedade Civil; em segundo lugar, demarcar-se-ão as questões atinentes às competências das entidades federativas neste ponto. Feito isto, vai se enfrentar como tem se dado a inserção do Poder Judiciário no particular, e o que isto implica em termos políticos e institucionais à Democracia Brasileira.

\section{A saúde como direito fundamental}

$\mathrm{O}$ direito à saúde no ordenamento jurídico contemporâneo se afigura como típico direito social, haja vista que constituye el eje alrededor del cual giran, a distancia mayor o menor, todos los otros. ${ }^{1}$ Significa dizer que

* Trecho do poema "De mãos dadas", de Carlos Drummond de Andrade.

A \& C R. de Dir. Administrativo e Constitucional, Belo Horizonte, ano 6, n. 25, p. 25-40, jul./set. 2006 
ele se apresenta como direito primário e absoluto, a partir do qual os demais direitos podem ser exercidos, e por esta razão inviolável.

Mas o que se entende por saúde aqui? A doutrina especializada na abordagem do tema trabalha com a lógica de que ela implica a integridade física e psíquica da pessoa humana. ${ }^{2}$ Assim, figurando o ser humano como centro de constituição categorial da idéia de saúde, é tal condição que estabelece os elementos necessários à sua definição jurídica, a saber: o direito à saúde dirige-se à proteção da pessoa humana contra quaisquer ameaças ou agressões que derivem das condições próprias dos locais de trabalho, da cidade ou de qualquer outro ambiente do mundo da vida.

En efecto, éste supone la titularidad de un bien natural y personal (la salud) respecto del cual todos los otros asociados están obligados a no tener comportamientos de peligro o de dano. Es por ello que el derecho a la salud puede definirse como derecho absoluto del individuo, que, como tal, puede hacerse valer tanto respecto del Estado y los poderes públicos en general como de las autoridades privadas (por exemplo lãs empresas) o, más en general, em las relaciones (paritarias) entre particulares, como ejemplo, entre productor y consumidor. $^{3}$

É a partir do século XX, com surgimento da Organização Mundial da Saúde (OMS), em 1946, que a saúde vai receber tratamento institucional - internacional e nacional — como o completo bem-estar físico, mental e social, portanto, para além da noção que envolve a ausência de doenças ou agravos, independente da condição social ou econômica do ser humano, de sua crença religiosa ou política.

A despeito disto, os direitos sociais, por pressuporem grandes disponibilidades financeiras pelo Estado, levaram os Estados Nacionais, como lembra Canotilho, a aderirem à construção dogmática da reserva do possível (Vorbehalt des Möglichen) para traduzir a idéia de que estes direitos só existem quando e enquanto existir dinheiro nos cofres públicos (tema que vamos abordar mais adiante).

Um direito social sob "reserva dos cofres cheios" equivale, na prática, a nenhuma vinculação jurídica. Para atenuar esta desoladora conclusão adianta-se,

\footnotetext{
BALDASSERE, 2002, p. 166

2 PERGUNSON, 2002, p. 39.

3 BALDASSERE, 2002, p. 173.
}

A \& C R. de Dir. Administrativo e Constitucional, Belo Horizonte, ano 6, n. 25, p. 25-40, jul./set. 2006 
por vezes, que a única vinculação razoável e possível do Estado em sede de direitos sociais se reconduz à garantia do mínimo social. Segundo alguns autores, porém, esta garantia do mínimo social resulta já do dever indeclinável dos poderes públicos de garantir a dignidade da pessoa humana e não de qualquer densificação jurídico-constitucional de direitos sociais. Assim, por exemplo, o "rendimento mínimo garantido" não será a concretização de qualquer direito social em concreto (direito ao trabalho, direito à saúde, direito à habitação) mas apenas o cumprimento do dever de socialidade imposto pelo respeito da dignidade da pessoa humana e pelo direito ao livre desenvolvimento da personalidade.... Não haverá um direito fundamental à saúde, mas um conjunto de direito fundados nas leis reguladoras dos serviços de saúde. ${ }^{4}$

Por estas razões é que o Texto Constitucional brasileiro de 1988 traz à saúde em diversos de seus dispositivos, dentre os quais, destacamos: arts. $5^{\circ}, 6^{\circ}, 7^{\circ}, 21,22,23,24,30,127,129,133,134,170,182,184,194$, 195, 197, 198, 199, 200, 216, 218, 220, 225, 227 e 230.

É, pois, aquele art. $6^{\circ}$, da Constituição Federal de 1988, que reconhece a saúde como um direito social. Partindo deste pressuposto, o direito à saúde passa a ser um direito que exige do Estado prestações positivas no sentido de garantia/efetividade da saúde, pena de ineficácia de tal direito. De outro lado, verificando-se que os direitos sociais localizam-se no Capítulo II, do Título II, da nossa Carta Magna, e este Título elenca os direitos e garantias fundamentais, pode-se concluir que os direitos sociais (como a saúde) são direitos fundamentais do homem. ${ }^{5}$

\section{Perspectivas institucionais do dever prestacional da saúde no Brasil}

Na medida em que o art. 196, da CF/88, trata a saúde como um direito de todos e dever do Estado, devendo ser garantida mediante políticas sociais e econômicas que visem à redução do risco de doença e de outros agravos e ao acesso universal e igualitário às ações e serviços para sua promoção, proteção e recuperação, tal dispositivo não pode ser interpretado como uma norma programática ${ }^{6}$ e, conseqüentemente, de eficácia limitada, posto que a saúde, para efeitos de sua aplicação, deve ser conceituada, segundo Schwartz como:

\footnotetext{
4 CANOTILHO, 2003, p. 443.

5 Ver neste sentido a interessante reflexão de FREIRE, 1997. Na mesma direção: DALLARI, 1995; KRAUNT, 1997.

6 Pois, se isto ocorresse, a nova Hermenêutica constitucional se desataria de seus vínculos com os fundamentos e princípios do Estado Democrático de Direito se os relegasse ao território das chamadas normas programáticas, recusando-Ihes concretude negativa sem a qual, ilusória a dignidade da pessoa humana não passaria também de mera abstração. BONAVIDES, 2004, p. 118.
}

A \& C R. de Dir. Administrativo e Constitucional, Belo Horizonte, ano 6, n. 25, p. 25-40, jul./set. 2006 
Um processo sistêmico que objetiva a prevenção e cura de doenças, ao mesmo tempo que visa a melhor qualidade de vida possível, tendo como instrumento de aferição a realidade de cada indivíduo e pressuposto de efetivação a possibilidade de esse mesmo indivíduo ter acesso aos meios indispensáveis ao seu particular estado de bem-estar. ${ }^{7}$

Na mesma senda anda parte significativa da jurisprudência brasileira, quando assevera que:

Descipienda de quaisquer comentários a discussão a respeito de ser ou não a regra dos arts. $6^{\circ}$ e 196 , da $\mathrm{CF} / 88$, normas programáticas ou de eficácia imediata. Nenhuma regra hermenêutica pode sobrepor-se ao princípio maior estabelecido, em 1988, na Constituição Brasileira, de que "a saúde é um direito de todos e dever do Estado" (art. 196).

Ora, nos parece totalmente inequívoco externar que o direto à saúde é um direito fundamental social, visto que, é possuidor de todas as características inerentes a estes direitos, haja vista o art. $5^{\circ}, \S 1^{\circ}$ da $\mathrm{CF} / 88$, que insere a saúde no rol dos direitos fundamentais explicitamente. E caso surgisse alguma controvérsia a respeito, podíamos nos socorrer a norma do art. $5^{\circ}, \S 2^{\circ}$ da nossa Lei Maior de 1988, ao qual, desencadearia o direito à saúde, embora não-escrito, como um direito fundamental implícito. ${ }^{8}$

Veja-se que também em nível de infraconstitucionalidade esta compreensão ampliada da saúde vem igualmente ratificada, haja vista, por exemplo, as disposições da Lei Federal $n^{0}$ 8.080/90 (Lei Orgânica da Saúde) que já em seu art. $2^{\circ}$ define que a saúde é um direito fundamental do ser humano, devendo o Estado prover as condições indispensáveis ao seu pleno exercício. Tal dever estatal consiste, nos termos do parágrafo primeiro deste Estatuto normativo, na formulação e execução de políticas econômicas e sociais que visem à redução de riscos de doenças e de outros agravos, e no estabelecimento de condições que assegurem acesso universal e igualitário às ações e aos serviços para a sua promoção, proteção e recuperação.

Por sua vez, o art. $3^{\circ}$, do mesmo dispositivo, assevera que a saúde tem como fatores determinantes e condicionantes, entre outros, a alimentação, a moradia, o saneamento básico, o meio ambiente, o trabalho, a renda, a educação, o transporte, o lazer e o acesso aos bens e serviços essenciais. Além disto, também lhe diz respeito todas as ações que, por força do disposto no artigo anterior, se destinam a garantir às pessoas e

\footnotetext{
7 SCHWARTZ, 2001, p. 39.

8 Recurso Extraordinário em Mandado de Segurança, n 11.183/PR, no voto do Relator Ministro José Delgado.
}

A \& C R. de Dir. Administrativo e Constitucional, Belo Horizonte, ano 6, n. 25, p. 25-40, jul./set. 2006 
à coletividade condições de bem-estar físico, mental e social.

O que está em debate aqui, pelos termos do prisma constitucional, é o que passo a chamar de mínimo existencial à dignidade da vida humana: a saúde. Enquanto princípio fundante de todo o sistema jurídico - a iniciar pelo constitucional -, tenho que a vida humana digna espelha e se vincula ao ideário político, social e jurídico predominante no país, ao mesmo tempo em que, na condição de princípio fundamental, em face de sua característica de aderência, ele opera sobre os comportamentos estatais ou particulares de forma cogente e necessária. Por tais razões tenho sustentado que: (a) todas as normas do sistema jurídico devem ser interpretadas no sentido mais concordante com este princípio; (b) as normas de direito ordinárias desconformes à constituição e seus princípios fundacionais (dentre os quais destaco o sob comento) não são válidas. ${ }^{9}$

Justifica-se tal postura em face de que a saúde como condição de possibilidade da dignidade da pessoa humana, em verdade, passa a constituir o que chamo de indicador constitucional parametrizante do mínimo existencial, ${ }^{10}$ porque se afigura como uma das condições indispensáveis à construção de uma Sociedade livre, justa e solidária; à garantia do desenvolvimento nacional; à erradicação da pobreza e da marginalização, bem como à redução das desigualdades sociais e regionais; à promoção do bem de todos, sem preconceitos de origem, raça, sexo, cor, idade e quaisquer outras formas de discriminação.

Na verdade, estes postulados estão dispersos ao longo de todo o Texto Político, consubstanciando-se nos direitos e garantias fundamentais, individuais e coletivos, nos direitos sociais, nos direitos à educação, à saúde, à previdência, etc. Por sua vez, os Poderes Estatais e a própria Sociedade Civil (através da cidadania ou mesmo de representações institucionais dela) estão vinculados a estes indicadores norteadores da República, eis que eles vinculam todos os atos praticados pelos agentes públicos e pela comunidade, no sentido de vê-los comprometidos efetivamente com a implementação daquelas garantias.

Se isto é verdade, quero sustentar que qualquer política pública no Brasil tem como função nuclear a de servir como esfera de intermediação entre o sistema jurídico constitucional (e infraconstitucional) e o mundo

\footnotetext{
${ }^{9}$ Neste sentido ver o texto de HESSE, 1991, p. 39.

10 Desenvolvo este argumento no livro: Estado, Sociedade e Administração Pública: novos paradigmas. Porto Alegre: Liv. do Advogado, 2005.
} 
da vida Republicano, Democrático e Social que se pretende instituir no país. Em outras palavras, é através de ações estatais absolutamente vinculadas/comprometidas com os indicadores parametrizantes de mínimo existencial previamente delimitados, que vai se tentar diminuir a tensão entre validade e faticidade que envolve o Estado e a Sociedade Constitucional e o Estado e a Sociedade Real no país. ${ }^{11}$

Isto me leva a crer na existência daquilo que vou chamar de políticas públicas constitucionais vinculantes, aqui entendidas como aquelas ações que o Texto Político atribui aos Poderes Estatais como efetivadoras de direitos e garantias fundamentais, e todas as decorrentes delas, haja vista os níveis compartidos de responsabilidades entre as entidades federativas brasileiras e a cidadania envolvendo a matéria. Considerando ainda crer, no particular, não existirem normas constitucionais despossuídas de concreção no sistema jurídico pátrio, ${ }^{12}$ resulta claro que a responsabilidade de que estamos falando aqui é, diferenciadamente, pró-ativa dos poderes instituídos, merecendo imediata implementação.

Na pertinente especificidade que dá o direito à saúde, Ingo Sarlet sustenta que ele pode ser considerado como constituindo simultaneamente direito de defesa, no sentido de impedir ingerências indevidas por parte do Estado e terceiros na saúde do titular, bem como impõe ao Estado a realização de políticas públicas que busquem a efetivação deste direito para a população, tornando, para além disso, o particular credor de prestações materiais que dizem com a saúde, tais como atendimento médico e hospitalar, fornecimento de medicamentos, realização de exames da mais variada natureza. ${ }^{13}$

De outro lado, as ações públicas voltadas à densificação material deste direito de todos integram um sistema único em todo o país (art. 198, $\mathrm{CF} / 88$ ), financiado com recursos do orçamento da seguridade social, da União, dos Estados, do Distrito Federal e dos Municípios, bem como de outras fontes.

Estas ações, sem exceção, precisam sempre estar amoldadas aos permissivos jurídicos atinentes, por exemplo, à execução de receitas e despesas públicas, sob pena de violação formal e material dos princípios e

\footnotetext{
${ }^{11}$ Há uma reflexão bastante interessante sobre as incoerências da operacionalidade do sistema capitalista, notadamente em economias demasiadamente dependentes, em UNGER, 1998.

12 Direção em que caminha a melhor doutrina constitucional do país, ex vi o percuciente trabalho de STRECK, 2004.

13 SARLET, 2001, p. 98.
}

A \& C R. de Dir. Administrativo e Constitucional, Belo Horizonte, ano 6, n. 25, p. 25-40, jul./set. 2006 
regras informativos da Administração Pública. Tal é o intento da Constituição Federal de 1988 ao vedar o início de programas ou projetos não incluídos na lei orçamentária anual (art. 167, inc. I), a realização de despesas que excedam os créditos orçamentários (art. 167, inc. II), bem como a transposição, o remanejamento ou a transferência de recursos de uma categoria de programação para outra, ou de um órgão para outro, sem prévia autorização legislativa (art. 167, inc. VI).

Tais indicadores normativos parametrizantes das ações públicas, portanto, aplicam-se também às políticas de saúde e as possibilidades de suas execuções.

Em face de todo este cenário, cumpre perquirir quais as responsabilidades das entidades federativas e dos poderes instituídos diante destas demandas, até para problematizar um dos argumentos reiterados para impor limitadores a este direito que é a anteriormente mencionada reserva do possível.

Neste sentido, atento às disposições jurídicas anteriormente referidas, percebe-se com facilidade que quando o sistema jurídico determina ao Estado o dever de prestar a saúde pública à população, não discrimina em termos de entidade federativa ou poder instituído, e o faz de forma coerente, pois, considerando que tais normas possuem caráter regulatório geral e também especial, a todos vincula, inclusive a Sociedade. ${ }^{14}$

Quando se afirma que o Poder Executivo é que detém a responsabilidade pela efetivação do direito à saúde garantido constitucional e infraconstitucionalmente, na verdade, quer-se dizer que é ele o responsável, juridicamente, pela dimensão operacional desta efetivação - sua possibilidade pragmática - , haja vista que tem a incumbência de gestar o plexo orçamentário (plurianual, diretrizes e orçamento anual) que se destina a isto, devidamente aprovado pelo Parlamento de cada entidade federativa (notadamente as prioridades públicas neste nível, transmutadas em rubricas orçamentárias a serem executadas).

A responsabilidade da Sociedade Civil aqui é igualmente importante, tanto na definição do perfil de Parlamento e do Chefe do Executivo que vai constituir - e que, por sua vez, vão definir quais são as questões que vão merecer atenção especial em termos de políticas públicas de saúde - , como no âmbito do controle destes Poderes, através de suas instituições organizadas, ou mesmo pela via individual do exercício dos

\footnotetext{
${ }^{14}$ Dispõe neste sentido $\circ \S 2^{\circ}$, do art. $2^{\circ}$, da Lei Federal $n^{\circ} 8.080 / 90$, no sentido de que este dever do Estado não exclui o das pessoas, da família, das empresas e da sociedade.
}

A \& C R. de Dir. Administrativo e Constitucional, Belo Horizonte, ano 6, n. 25, p. 25-40, jul./set. 2006 
direitos da cidadania.

Já no que tange às entidades federativas, de forma gramatical, a ordem constitucional vigente determinou a responsabilidade solidária para os fins de cuidado com a saúde pública, nos termos do art. 23, II, do Texto Político. ${ }^{15}$

Se todas estas disposições estabelecem diretrizes e regras obrigando o Estado (independente de esfera de poder ou entidade federativa) a efetivar o direito à saúde, não fixam critérios para estabelecer a dossimetria de tal obrigação, o que traz problemas à densificação material desta responsabilidade, matéria que vamos enfrentar, mais tarde, à luz dos elementos constitutivos do próprio sistema jurídico (numa perspectiva da Teoria do Direito).

A Lei Estadual gaúcha de $n^{\circ} 9.908 / 93$, por exemplo, determina que o Estado forneça, gratuitamente, medicamentos excepcionais, assim compreendidos aqueles de uso contínuo, às pessoas que não puderem arcar com as despesas do tratamento, sem privação do próprio sustento e da família. Todavia, quando assim disciplina, o faz para toda a sociedade gaúcha, não fazendo diferenciação entre os que possuem $x$ ou $y$ tipo de enfermidade - o que inclusive seria vedado pelo Princípio Constitucional da Igualdade e Impessoalidade vigentes.

Assim, no âmbito do dever público para prestar estes medicamentos, o que temos de ter em conta são os critérios utilizados para determinar quem efetivamente necessita do auxílio do Estado para prover suas demandas a este título e quem não precisa, o que de plano se sabe não existir, ao menos em numerus clausulus, porque impossível a matematização desta questão em face de sua natureza complexa e mutável.

Veja-se que a leitura do art. 197, da Constituição Federal, autoriza conclusão no sentido de que ao Estado cabe garantir a saúde e as diretrizes e políticas que a constituem, todavia, sua execução pode ser levada a cabo pelo próprio Estado, ou através de terceiros. Salvo melhor juízo, entendese por terceiros também a iniciativa privada e o Mercado, situação que efetivamente ocorre no cenário nacional. Ora, sabendo-se que os recursos que sustentam a iniciativa privada e o Mercado são hauridos pela forma

\footnotetext{
${ }^{15}$ Assim é que, de forma recorrente, os Tribunais de Justiça em geral, e em especial o Tribunal de Justiça do Rio Grande do Sul, têm reconhecido o dever do Estado, independente da entidade, em garantir ao cidadão o direito à saúde.
}

A \& C R. de Dir. Administrativo e Constitucional, Belo Horizonte, ano 6, n. 25, p. 25-40, jul./set. 2006 
de subsídios e contraprestações dos usuários, e levando em conta que este setor está habilitado constitucional e infraconstitucionalmente para prestar serviços desta natureza, não é crível extrair daqui a premissa de que o serviço público de saúde deva ser absoluta e universalmente gratuito e responsável exclusivo pelo atendimento de tamanha demanda, até porque a fonte de recursos estatais para tal mister decorre de contribuições de natureza fiscal e extra-fiscal, restritas em termos de limites e atribuições.

Alia-se a isto a responsabilidade da Sociedade Civil neste âmbito, destacada anteriormente, devendo responder por sua quota de participação na gestão da saúde, por exemplo, desonerando o Estado desta atividade de acordo com suas possibilidades.

Por isto é que cada demanda de saúde submetida ao Estado é merecedora de uma apreciação e ponderação em face de, no mínimo, duas variáveis necessárias: (a) a variável qualitativa-normativa-constitucional (e infraconstitucional), enquanto direito fundamental assegurado à sociedade brasileira e compartida dentre todos os atores envolvidos; (b) a variável quantitativa-orçamentária, em face das possibilidades materiais limitadas do atendimento de demandas cada vez mais ilimitadas.

Estas duas variáveis mínimas elencadas não são excludentes ou concorrentes umas em relação às outras, mas integrativamente seqüenciais, eis que a primeira é marco fundacional da segunda, e esta, condição não exclusiva (mas importante) da efetividade da primeira. Daí porque aferir, prima facie, a natureza axiológico-constitucional do direito à saúde sob comento, tendo ciência que ele se dirige a toda a comunidade, e não a uma parcela dela (os mais doentes, ou somente aqueles que possuem enfermidades letais, ou somente os que necessitam de farmacológicos curativos, etc.).

Significa dizer que, quando se fala em saúde pública e em mecanismos e instrumentos de atendê-la, mister é que se visualize a demanda social e universal existente, não somente a contingencial submetida à aferição administrativa ou jurisdicional, isto porque, atendendo-se somente aqueles que acorrem de pronto ao Poder Público (Executivo ou Judicial), pode-se correr o risco de esvaziar a possibilidade de atendimento de todos aqueles que ainda não tomaram a iniciativa de procurar o socorro público, por absoluta falta de informações ou recursos para fazê-lo.

Por outra via, se a Administração Pública não construiu critérios razoáveis e ponderados para escalonar minimamente o atendimento cada

A \& C R. de Dir. Administrativo e Constitucional, Belo Horizonte, ano 6, n. 25, p. 25-40, jul./set. 2006 
vez mais massivo de perquirições envolvendo o oferecimento de medicamentos à população carente, e tampouco o legislativo, então isto deverá ser feito na esfera da judicialização do debate, sempre tendo em conta que a satisfação de um problema imediato poderá inviabilizar centenas de outros tão importantes e legítimos quanto este, haja vista que os recursos financeiros e materiais para tanto, é inexorável, são finitos.

Daqui tem-se extraído a tese de que a efetivação dos direitos sociais depende de um universo de recursos financeiros que precisam respeitar a reserva do possível - atinentes à disponibilidade orçamentária do Poder Público - , retirando de tal equação as quotas de responsabilidade que tanto o Mercado como a Sociedade possuem. É como se somente o Estado tivesse de arcar com a prestação de serviços de saúde. Em outras palavras, por força da indigitada limitação de recursos, tem-se defendido que apenas o "mínimo existencial" poderia ser garantido, isto é, apenas direitos sociais, econômicos e culturais considerados mais relevantes, em face do caso concreto, por integrarem o núcleo da dignidade da pessoa ou por decorrerem do direito básico da liberdade, impor-se-iam erga omnes e seriam diretamente sindicáveis. ${ }^{16}$

Por tais razões é que Alexy insiste, e com ele concordo, na tese de que apenas quando a garantia material do padrão mínimo em direitos sociais puder ser tida como prioritária, estando presente uma restrição proporcional dos bens jurídicos (fundamentais ou não) colidentes, há como se admitir um direito subjetivo à determinada prestação social. ${ }^{17}$

Ingo Sarlet, no particular e de forma oportuna, lembra que a expressão reserva do possível, consoante jurisprudência do Tribunal Constitucional Alemão, abrange tanto a possibilidade quanto o poder de disposição por parte do destinatário da norma, deduzindo que a prestação reclamada deve corresponder ao que o indivíduo pode razoavelmente exigir da sociedade, de tal sorte que, mesmo em dispondo o Estado de recursos e tendo o poder de disposição, não se pode falar em uma obrigação de prestar algo que não se mantenha nos limites do razoável. ${ }^{18}$

Na seqüência deste raciocínio quero propor, com Konrad Hesse, que o operador do direito, tratando de questões desta natureza, não se esqueça de forjar as possibilidades de respostas destas demandas utilizando

\footnotetext{
${ }^{16}$ ALEXY, 1998, p. 39.

17 ALEXY, 1998, p. 42

18 SARLET, 2004, p. 281
}

A \& C R. de Dir. Administrativo e Constitucional, Belo Horizonte, ano 6, n. 25, p. 25-40, jul./set. 2006 
o que o autor alemão chama de princípio da concordância prática ou da harmonização, o qual impõe ao intérprete do sistema jurídico que os bens constitucionalmente protegidos, em caso de conflito ou concorrência, devem ser tratados de maneira que a afirmação de um não implique o sacrifício do outro, o que só se alcança na aplicação ou na prática do texto. ${ }^{19}$ Tal princípio parte exatamente da noção de que não há diferença hierárquica ou de valor entre os bens constitucionais; destarte, o resultado do ato interpretativo não pode ser o sacrifício total de uns em detrimento dos outros. Deve-se, na interpretação, procurar uma harmonização ou concordância prática entre os bens constitucionalmente tutelados.

Numa perspectiva integrada do sistema jurídico, estou a dizer, ainda com Hesse, que na resolução dos problemas jurídico-constitucionais, deve-se dar prioridade às interpretações ou pontos de vista que favoreçam a integração política e social, possibilitando o reforço da unidade política, porquanto essas são as finalidades precípuas da Constituição.

A partir de tais considerações é que a matéria vertente precisa ser enfrentada, ponderando os bens jurídicos que estão em jogo e que demandam abordagem à solução do caso: o bem jurídico vida dos indivíduos, envolvendo a moléstia de que estão acoimados, correlato ao dever do Estado para com a saúde pública; o bem jurídico saúde pública de toda a Sociedade para com quem este mesmo Estado possui o dever de tutela. Tal ponderação não resta limitada por critérios quantitativos como os atinentes às possibilidades orçamentárias (lógica da reserva do possível), isto porque ela se dá num momento anterior que é o do próprio tensionamento da fundamentação dos direitos e bens envolvidos, a partir do que será indicado o que deve ser garantido e em que medida. ${ }^{20}$

No âmbito do estabelecimento dos juízos de ponderação destes bens, valores e interesses, para se chegar a alguma conclusão, tenho que se deve lançar mão de critérios constitucionalmente consagrados à delimitação dos índices materiais de fundamentalidade desses direitos, a saber, os que densificam o princípio da proporcionalidade dentre eles.

Na dicção de Robert Alexy, por exemplo, o princípio da proporcionalidade desdobra-se em três aspectos fundamentais: a) adequação;

\footnotetext{
${ }^{19} \mathrm{HESSE}, 2001$, p. 119. Fala o autor, aqui e na verdade, da tese de que, na interpretação constitucional, deve-se dar primazia às soluções ou pontos de vista que, levando em conta os limites e pressupostos do texto constitucional, possibilitem a atualização de suas normas, garantindo-lhes eficácia e permanência constante.

${ }^{20}$ Estou falando, por exemplo, do momento de definição do plexo orçamentário (plurianual, diretrizes e orçamento anual) pela via do processo legislativo, e mesmo o da sua execução.
}

A \& C R. de Dir. Administrativo e Constitucional, Belo Horizonte, ano 6, n. 25, p. 25-40, jul./set. 2006 
b) necessidade (ou exigibilidade); c) proporcionalidade em sentido estrito. A adequação significa que o intérprete deve identificar o meio adequado para a consecução dos objetivos pretendidos. A necessidade (ou exigibilidade) significa que o meio escolhido não deve exceder os limites indispensáveis à conservação dos fins desejados. A proporcionalidade em sentido estrito significa que o meio escolhido, no caso específico, deve se mostrar como o mais vantajoso para a promoção do conjunto de valores, bens e interesses em jogo. ${ }^{21}$

Com este ferramental hermenêutico ao menos se pode aferir com maior fundamentação e argumentação públicas - que se submetem à interlocução entre as partes envolvidas no feito, inclusive para fins decisionais e recursais - quais as razões de justificação da intervenção judicial no âmbito da saúde.

A partir disto se podem avaliar como estas abordagens do tema devem ser aplicadas na solução de um caso concreto.

\section{0 caso concreto e sua solução}

O caso que se apresenta à testificação da proposta de abordagem do direito à saúde até aqui construída, trata de Agravo de Instrumento ${ }^{22}$ interposto junto a Terceira Câmara Cível, do Tribunal de Justiça do Estado do Rio Grande do Sul, Brasil, em face de decisão que indeferiu a antecipação de tutela pleiteada na ação ordinária ajuizada contra o Estado do Rio Grande do Sul, à concessão de medicamentos pleiteados (no montante de $\mathrm{R} \$ 10.200,00$ — dez mil e duzentos reais), sob o fundamento de que " Os atestados médicos que acompanharam a exordial não apontam a necessidade imediata do fornecimento do medicamento reclamado, assim como o parecer emitido pelo Departamento Médico Judiciário. Diuturnamente, as Varas da Fazenda recebem pedidos para fornecimento de medicação indispensável à vida e saúde da população, pedidos estes que enfrentam inúmeras dificuldades quanto ao cumprimento das ordens exaradas pelos juízos. Ora, o custo do medicamento em questão é inúmeras vezes superior à soma de outros tantos remédios, estes sim imprescindíveis para o salvamento de outras pessoas". ${ }^{23}$

Em suas razões, a Agravante defendeu, em síntese, a possibilidade da concessão da liminar, diante da gravidade de sua situação, com seqüelas motoras importantes, mostrando-se necessário o uso do medicamento

\footnotetext{
${ }^{21}$ ALEXY, 2000, p. 126.

${ }^{22}$ RIO GRANDE DO SUL. Tribunal de Justiça. Agravo de Instrumento n 70013407242 . Órgão julgador: $3^{a}$ Câmara. Relator: Des. Rogério Gesta Leal. Julgado em 08 nov. 2005.
}

A \& C R. de Dir. Administrativo e Constitucional, Belo Horizonte, ano 6, n. 25, p. 25-40, jul./set. 2006 
pleiteado em virtude de outros remédios não surtirem mais efeitos, e em virtude de constituir dever do Estado a promoção da saúde, nos termos do artigo 196, da Constituição Federal.

Há a referência de que a demora no tratamento implicaria a evolução da doença, o que viria a provocar "... atrofias e deformidades severas, perda funcional e dependência de outras pessoas para necessidades básicas diárias", justificando a concessão da tutela antecipada pretendida.

Em termos normativos à análise do caso, além dos dispositivos constitucionais referidos, tem-se que a Lei Estadual gaúcha de no 9.908/93 determina que o Estado forneça, gratuitamente, medicamentos excepcionais, assim compreendidos aqueles de uso contínuo, às pessoas que não puderem arcar com as despesas do tratamento, sem privação do próprio sustento e da família.

O que deveria ser perquirido, em face destas considerações e para a solução do caso concreto, é o seguinte: (a) qual o meio mais adequado para se conseguir atender o problema apresentado pela demandante, levando em conta o universo em que ele está situado (em meio a um contingente sem fim de reivindicações similares, diante de recursos públicos cada vez mais escassos)? Por certo é aquele que espanque as dúvidas, de forma convincente, mesmo em caráter precário, quanto a inexistência de qualquer outro tratamento ou medicamento que não o postulado na inicial!; (b) é necessário mesmo a medicação recomendada e postulada pela paciente-autora, em face da necessidade de se pesquisarem outras maneiras e fórmulas de atendimento da demanda, porque milhares de postulações estão acorrendo aos cofres públicos neste momento?; (c) a antecipação de tutela, neste momento processual, sem nenhuma tentativa de se avaliarem outras alternativas, gerando um investimento estatal razoável de recursos públicos, afigura-se como o meio mais vantajoso à promoção dos valores, interesses e bens que a saúde pública (individual e social) pretende albergar?

Na espécie, conforme se verificou do laudo médico acostado nos autos, o parecer do Departamento Médico Judiciário- DMJ asseverou que não há menção do estado clínico atual da autora pela sua médica assistente. Não

\footnotetext{
${ }^{23}$ A Agravante, em verdade, é portadora de Artrite Reumatóide (CID M06.9), conforme os prontuários juntados aos autos, necessitando fazer uso contínuo do medicamento Infliximab 100mg, com custo aproximado de $\mathrm{R} \$ 10.200,00$ (dez mil e duzentos reais) para o tratamento.
}

A \& C R. de Dir. Administrativo e Constitucional, Belo Horizonte, ano 6, n. 25, p. 25-40, jul./set. 2006 
havendo, no momento, manifestações sistêmicas graves e refratárias ao tratamento sem infliximabe, razão pela qual opinou pela realização de perícia a fim de avaliar mais precisamente a indicação do uso do medicamento em questão.

Foi com base neste parecer que a douta magistrada de primeiro grau indeferiu a tutela antecipada, o fazendo muito bem, a meu sentir, isto porque é com as informações da perícia realizada pelo Estado (que deve pagar a conta deste tratamento) que se podem ter respostas mais convincentes para os interrogantes anteriormente elencados, necessárias à melhor solução do caso, sem o comprometimento radical dos interesses públicos indisponíveis que estão em jogo.

Vale a pena referir ainda que, em sede de antecipação de tutela pretendida pela Agravante, o instituto encontra-se inscrito no art. 273, caput, do CPC, na redação dada pela L. 8.952, perquirindo pressupostos essenciais para ser deferido, no todo ou em parte, dizendo respeito aos efeitos da tutela pleiteada no pedido inicial. Assim, terá cabimento a antecipação "desde que, existindo prova inequívoca", o juiz "se convença da verossimilhança da alegação" do requerente - e além disso, é claro, ocorra alguma das situações previstas nos incisos I e II.

Ocorre que não se tem mostrado inteiramente pacífica, para dizer o menos, a convivência entre os dois pressupostos: o da "prova inequívoca" e o da "verossimilhança da alegação". Doutrina e jurisprudência enleiamse em dificuldades quando tratam de explicar essa conjugação. Deixa certo a lei que, para a concessão do provimento antecipatório, basta a convicção de ser "verossímil" a alegação do requerente, isto é, não se exige a certeza de que ela seja veraz.

Neste ponto, tenho, com Barbosa Moreira, que a força persuasiva da prova, a sua capacidade para persuadir o juiz, está suficientemente assinalada no texto legal que demarca o instituto, pela oração "desde que (...) se convença da verossimilhança da alegação". Se é indispensável que o juiz se convença, e se o convencimento do juiz não se pode basear senão em alguma prova, dizer que essa prova tem de ser convincente é dizer o mesmo que está dito alhures acerca do juiz. Gira-se num círculo vicioso: o juiz deve convencer-se da verossimilhança da alegação, e a prova deve ser tal que disso o convença. ${ }^{24}$

Outro pressuposto da antecipação da tutela vem expresso, em forma negativa, no $§ 2^{\circ}$, do art. 273 , do mesmo diploma. Esse dispositivo exclui o cabimento da antecipação "quando houver perigo de irreversibilidade

A \& C R. de Dir. Administrativo e Constitucional, Belo Horizonte, ano 6, n. 25, p. 25-40, jul./set. 2006 
do provimento antecipado". Em relação a isto, a doutrina predominante relaciona a irreversibilidade com os efeitos do provimento antecipatório. A eles é que se refere, com técnica defeituosa, o $2^{\circ}$, do art. 273. Não se antecipará a tutela quando houver perigo de que a concessão gere efeitos irreversíveis. ${ }^{25}$

Quero concluir com isso que, bem pesadas as coisas, as considerações que se acabam de fazer refletem a idéia de que, na antecipação da tutela, como em todo assunto relativo ao processo, é mister levar em conta a bilateralidade que informa o fenômeno litigioso. Ora, tal pressuposto deve inspirar-nos a preocupação de evitar que, no funcionamento de qualquer mecanismo, uma das partes recolha sozinha as vantagens, enquanto se deixa a outra a gemer sob o peso dos inconvenientes.

Nestes casos, como bem pondera Marinoni:

Deve ocorrer a ponderação dos bens jurídicos em jogo, aplicando-se o princípio da proporcionalidade, pois quanto maior for o valor jurídico do bem a ser sacrificado, tanto maior deverá ser a probabilidade da existência do direito que justificará o seu sacrifício. É claro, no entanto, que o bem que tem valor jurídico largamente superior ao daquele com quem confronta não poderá ser sacrificado. ${ }^{26}$

Em face de todos estes argumentos é que se me afigura correto o indeferimento de pleito antecipatório em face de parcos e pouco conclusivos elementos atinentes a real necessidade, em nível de emergência, da exclusiva medida postulada, tema que deve ser aferido a partir de instrumentos e instrução probatória que não periclite de forma letal o bem jurídico tutelado (vida), no particular.

\section{Referências}

ALEXY, Robert. Colisão e ponderação como problema fundamental da dogmática dos direitos. Revista Fundação Casa de Rui Barbosa, Rio de Janeiro, v. 34, 1998.

ALEXY, Robert. Teoría de los derechos fundamentales. Madrid: Centro de Estudios Constitucionales, 2000.

BALDASSERE, Antonio. Los derechos sociales. Colômbia: Univesidad Externado de Colômbia, 2002.

BERMUDES, Sergio. A reforma do Código de Processo Civil. 2. ed. São Paulo: Saraiva, 1996.

BONAVIDES, Paulo. Curso de direito constitucional. São Paulo: Malheiros, 2004.

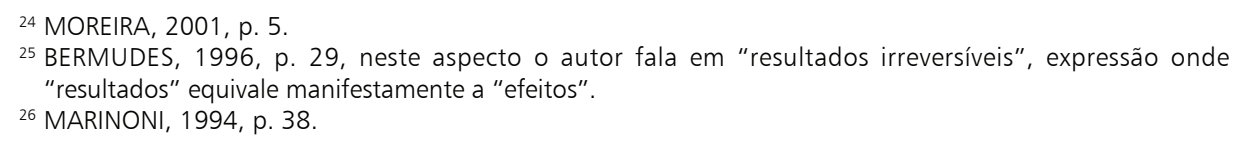

A \& C R. de Dir. Administrativo e Constitucional, Belo Horizonte, ano 6, n. 25, p. 25-40, jul./set. 2006 
CANOTILHO, José Joaquim Gomes. Direito constitucional e Teoria da Constituição. Lisboa: Almedina, 2003.

DALLARI, S. G. Os estados brasileiros e o direto à saúde. São Paulo: Hucitec, 1995.

FREIRE, A. M. P. La garantia em el Estado constitucional de derecho. Valladolid: Trotta, 1997.

HESSE, Konrad. A força normativa da Constituição. Porto Alegre: Fabris, 1991.

KRAUNT, J. A. Los derechos de los pacientes. Buenos Aires: Abeledo Perrot, 1997.

LEAL, Rogério Gesta. Estado, Sociedade e Administração Pública: novos paradigmas. Porto Alegre: Liv. do Advogado, 2005.

MARINONI, Luiz Guilherme. Efetividade do processo e tutela antecipatória. In: (Org.). O processo civil contemporâneo. Curitiba: Juruá, 1994.

MOREIRA, José Carlos Barbosa. Antecipação da tutela: algumas questões controvertidas. Revista Síntese de Direito Civil e Processual Civil, São Paulo, n. 13, p. 5-13, set./out. 2001.

PERGUNSON, Thomas. The health as right. New York: Bennimonn, 2002.

SARLET, Ingo W. A eficácia dos direitos fundamentais. Porto Alegre: Liv. do Advogado, 2004.

SARLET, Ingo W. Algumas considerações em torno do conteúdo, eficácia e efetividade do direito à saúde na Constituição de 1988. Interesse Público, São Paulo, n. 12, 2001.

SCHWARTZ, G. A. D. Direito à saúde: efetivação em uma perspectiva sistêmica. Porto Alegre: Liv. do Advogado, 2001.

STRECK, Lênio Luis. Jurisdição constitucional. Rio de Janeiro: Forense, 2004.

UNGER, Roberto Mangabeira. Democracy realized. New York: Verso, 1998.

Informação bibliográfica deste texto, conforme a NBR 6023:2002 da Associação Brasileira de Normas Técnicas (ABNT):

LEAL, Rogério Gesta. A efetivação do direito à saúde por uma jurisdição-serafim: limites e possibilidades. A\&C Revista de Direito Administrativo e Constitucional, Belo Horizonte, ano 6, n. 25, p. 25-40, jul./set. 2006.

A \& C R. de Dir. Administrativo e Constitucional, Belo Horizonte, ano 6, n. 25, p. 25-40, jul./set. 2006 